\title{
Unreasonable expectations - NHS IT, Greek choruses and the games institutions play around mega-programmes
}

\author{
Chris Sauer ${ }^{1}$, Leslie Willcocks ${ }^{2}$ \\ ${ }^{1}$ Saïd Business School and Templeton College, Oxford University, Oxford, UK \\ ${ }^{2}$ London School of Economics, London University, UK \\ Correspondence: \\ C Sauer, Saïd Business School and Templeton College, Oxford University, Oxford, UK. \\ Tel: + 44 (0) 186542 2755; \\ E-mail: chris.sauer@said-business-school-oxford.ac.uk
}

Journal of Information Technology (2007) 22, 195-201. doi:10.1057/palgrave.jit.2000108

\section{Introduction}

0 ur current issue focusses on an area in the application of information technology (IT) that is critical for both society and the modern economy - health. In particular, we focus on the National Health Service (NHS) in the United Kingdom where ongoing national and local programmes have attracted widespread national and international attention.

Exploitation of information offers benefits in numerous ways. Remote monitoring of heart conditions via the technology of telemedicine can bring patients to the hospital before a critical incident occurs. 3-D modelling can give doctors better images of the body by which to target therapies. Results reporting systems offer more rapid access to test results. Patient administration and booking systems facilitate efficient and effective administration. Shared medical record systems can make available essential history to maximise the probability of appropriate treatment in emergencies. Information mining can identify optimal clinical pathways to achieve the most successful ways of diagnosing and treating specific sets of symptoms. The e-health vision is clinically, economically, socially and politically attractive.

No country has found it easy to realise this vision of fully informatised health. Many reasons have contributed. The professional bureaucratic structure embodies tensions between clinicians and managers. Political interference has been widespread. State health systems tend to be large, so the IT projects are large and by definition risky. Investment in systems as against investment in hospitals and treatments is hard to justify. Re-thinking and reengineering the practice of health has too often been ignored in favour of the optimistic, though false, belief that implementing new IT alone will suffice.
Looming over us is the shadow of the UK NHS's continuing mega-programme, the National Programme for IT. It serves as a fascinating case study for this issue. It also raises questions about mega-programmes that have wider importance for our journal. The traditional approach of academics and consultants to analysing such a case is to contrast progress against plans and outcomes against targets, and to analyse what deficiencies of project management have led to the sub-optimal result achieved. More recently, though, there has been some emerging discourse in both practice and the Academy arguing for a more realistic approach to targets and to the assessment of performance. Bent Flyvbjerg and his colleagues (Flyvbjerg et al., 2003) talk of strategic optimism - the practice of understating costs and overstating benefits. The concept of optimism bias is in common usage among practitioners as a problem for which the antidote is the business case. Indeed, the UK Government's Office of Government Commerce would claim that it explicitly includes allowance for optimism bias in its business cases (Office of Government Commerce, 2007). But we have seen too many optimistic business cases to believe that they consistently embody realistic assessments of what is possible (Sauer, 1993; Willcocks and Lester, 1999). So, if programmes too often start with unrealistic targets, the problem of project performance can be turned on its head and viewed as productively as a problem of misplaced expectations as a problem of mismanagement. This reversal of the analytical focus is most obviously worthy of investigation in the case of mega-projects and programmes where the sheer scale almost necessarily implies that progress will not be to plan, and outcomes will not be those originally agreed. 
In this editorial, we want to examine the issue of expectations. We know that in the delivery of a multi-year, multi-billion pound programme, problems are to be expected and that it is a misunderstanding of the nature of the enterprise to suppose that initial expectations will be met. Specifically, then, why is there such a fuss around the delays and mounting costs of the National Programme for IT? We argue that the programme is caught at the heart of institutional webs that benefit from taking a simplistic view of mega-programmes. The public interest will be better served by the widespread recognition of the complex and indeterminate nature of such programmes.

We start by offering a summary of the evolution and development of Connecting for Health and the emerging battery of criticisms. We offer a pragmatic assessment of what should have been expected. We describe the web of institutions that has been the source of these criticisms and examine the various institutional rationales. We offer one example of how these institutions may act on assumptions about those they serve that are incorrect and argue that it may be possible over time to develop a more realistic and informed public debate about mega-programmes in a way that will better serve the public interest.

\section{The National Programme for IT - a summary history}

The current UK government has long recognised that its predecessors underinvested in health IT. An initial strategy document in 1998 started the move towards redressing this. A more detailed strategy, Delivering 21st Century IT Support for the NHS - A National Strategic Programme, was published in June 2002. This served as the launch point for the setting up and funding of the National Programme for IT. The Programme's challenge has been to establish a shared health IT infrastructure to embody common functionality for a range of applications including patient care records, appointment booking, prescriptions and a data communications spine to permit record transfer throughout England. In October 2002, Richard Granger, then a partner at Deloitte Consulting, was appointed to lead the programme.

It is difficult to provide a precise calculation of the scale of the programme. By common consent, it is the largest civil programme in the world (see Sean Brennan, in this issue). As such, it was never going to be easy to procure. The strategy adopted was to break the programme into five regional geographies, each comprising a number of Strategic Health Authorities. Contracts were then put out to tender for systems-integrator-led consortia to act as Local Service Providers (LSP) for each region, or cluster, plus one contract for the national communications spine. Integral to the plan was the common functional and data architecture that would ensure that, however the LSP chose to source their technology, the outcome for the NHS and patients would be similar.

An initial figure of approximately $£ 6$ billion was quoted for the programme cost based on the sum of the major contracts. The systems integrators who won the work were contracted to deliver according to agreed schedules and were required to secure adoption of the technology in order to be fully paid. At this stage, the programme remained largely independent of the NHS Modernisation Programme, which was focussed on re-engineering health processes. In 2005, Connecting for Health was established as an agency to deliver the National Programme.

Since its inception in 2002/2003, the National Programme has encountered turbulent waters on a number of occasions. These have included:

- Turnover of senior responsible owners

- LSP doubts about their own capability

- Accenture's departure as an LSP in two regions, and their replacement by CSC

- Commercial viability problems relating to one supplier iSoft

- Announcements of delays

- Recognition that the full cost of the transformation associated with Connecting for Health will be a multiple of the procurement cost

- Stories of implementation problems in hospitals, often affecting patients

- Clinician alienation and critique

- Re-structuring of the programme

- Chronic critical commentary from the press, House of Commons Committee of Public Accounts (PAC) and 'the 23 academics' (notably, House of Commons Committee of Public Accounts (2007a,b) and Brian Randall in this issue)

- Resignation of Richard Granger, Director-General of NHS IT, announced in June 2007.

\section{The dilemmas of managing a mega-programme}

In this section, we take the scale of the mega-programme as given. We treat each of the elements of turbulence listed in the previous section as a function of the extraordinary scale of the National Programme for IT. Each can be seen as an outcome of the need to make judgements about the dilemmas of managing this scale where precedents and best practices are few or non-existent. These judgements and their outcomes can therefore be seen as neither unreasonable nor particularly surprising.

Mega-programmes exhibit various distinctive characteristics. Table 1 summarises characteristics relevant for the current argument. Each element can be seen to be an unsurprising implication of a standard characteristic.

Turnover of key personnel in projects is statistically associated with reduced scope, increased costs and schedule delays (Sauer et al., 2007). The turnover of some key personnel is always to be expected in a mega-programme. The turnover of Senior Responsible Owners in this case therefore was not surprising - even more it is, in fact, historically typical of the British civil service. The management dilemma is always whether to secure the highest quality individuals, individuals who will typically be ambitious to move on before the programme is completed, or to secure individuals who are willing to be shackled but who may lack the drive and quality of the very best. Either choice carries risks for the programme.

Mega-programmes typically put abnormal stress on the supply chain. The number of suppliers who have both the financial standing and the capability to manage such scale is small. They also have existing business to resource. In this case, the chairman of BT expressed concerns at an early stage, saying that his company was, 'somewhat frightened 
Table 1 The effects of scale on mega-programmes

\begin{tabular}{|c|c|}
\hline Characteristic & Typical effects \\
\hline Very long-time frame & $\begin{array}{l}\text { External volatility more likely, turnover of key personnel } \\
\text { unavoidable }\end{array}$ \\
\hline Impossibility of planning accurately & Changes to budget, schedule and scope \\
\hline $\begin{array}{l}\text { Unpredictability of how the programme process } \\
\text { will evolve }\end{array}$ & $\begin{array}{l}\text { Relationships ebb and flow. Some parties to the programme will } \\
\text { lose commitment }\end{array}$ \\
\hline Vast number of stakeholders/users & $\begin{array}{l}\text { Meaningfully engaging and communicating with all stakeholders/ } \\
\text { users is impossible }\end{array}$ \\
\hline Normal project uncertainty on a massive scale & $\begin{array}{l}\text { All the normal project delivery problems are to be expected but } \\
\text { because of scale and complexity their potential impact is massive }\end{array}$ \\
\hline Accumulation of problems & $\begin{array}{l}\text { Encourages the naysayers and promotes the tendency to criticise } \\
\text { thereby damaging reputation }\end{array}$ \\
\hline
\end{tabular}

by the enormity and complexity' of two such large contracts. Accenture subsequently negotiated its exit from its two contracts, apparently because they feared substantial losses. One Fujitsu senior manager has also expressed reservations as well as support, although these have been treated as more a personal rather than official company position (see evidence from Andrew Rollerson in House of Commons Committee of Public Accounts, 2007a). At the largest size, any supplier can be excused for having misgivings about its ability to deliver - we are at the outer reaches of known territory. The dilemma is that to bring in more suppliers by increasing the number of contracts and reducing their size is to introduce greater complexity of contract management and management of the interfaces among suppliers. It is also to introduce less financially stable companies who are less well equipped to ride out the turbulence endemic in the mega-programme.

External volatility takes many forms. The longer the programme, the more likely it is that externally triggered problems will arise. In the case of iSoft, the independent software company producing one of the patient record systems, the programme has been exposed to risk because the company has been accused of improper accounting practices that suggested that it has been more financially sound than in reality. It is, of course, easy in retrospect to argue that due diligence should have exposed this. In practice, the dilemma is that if a mega-programme tries to cover every possible source of risk, it will extend the cost and time frame beyond anything that is practically acceptable. It is more reasonable to treat such problems as natural turbulence.

Connecting for Health has announced delays to its original implementation plans. We would argue that no programme on this scale has plans that run like clockwork. In fact, in both public and private sector large-scale outsourcing projects, we regularly find the contract and timelines out of date the minute the ink on the contract is dry. Most such projects are subject to serious restructuring within 18-30 months (Willcocks and Lacity, 2006). Because it is impossible to anticipate all the possible ways in which risks may be realised, plans are inevitably optimistic. Delays are par for the course. We shall return to the issue of optimism shortly, but it is worth noting here that one dilemma mega-programmes face is that the more contingency they build into plans to account for the unpredicted, the longer the time frames and the less urgency team members feel. Experience shows that they then make too little progress early, leading to delay. But on the other side of the dilemma, an approach that accepts multiple schedule delays can equally demotivate.

There is a natural tendency in mega-programmes to downplay their full cost for fear of frightening off the funders. The initial costs of the National Programme for IT were stated as $£ 6$ billion based on the procurement costs. By April 2007, the House of Commons Committee of Public Accounts (2007a) was recording the planned national expenditure as $£ 4.1$ billion and related local expenditure as $£ 8.3$ billion. One could safely predict, on our experience of mega-projects, that these figures will continue to rise to at least three times the original estimates, that is in excess of $£ 18$ billion. And indeed this would have been a sensible benchmark to have adopted in 2003, suggested by widespread previous research into mega-programmes (see e.g. Willcocks and Griffiths, 1994; Willcocks and Graeser, 2001). The issue of what is more in the public interest, a full and honest appraisal of the real costs that might prevent the programme from starting or an appraisal that will get things under way and will lead to a range of benefits but where the business case is never proven, is a key part of the argument about what are reasonable and appropriate expectations for mega-programmes.

Mega-programmes can be expected to encounter the normal problems of projects that derive from uncertainty and complexity many times over. They also can expect that the increased complexity that is a common, if not necessary, consequence of scale will increase the probability of problems, particularly at points of interdependence such as organisational boundaries and interfaces. The implementation problems that started to emerge in the press at places such as Oxford's Nuffield Orthopaedic Hospital can be considered normal. There, introduction of a new system over December and January 2005/2006 caused the hospital trust to define its experience in terms of a serious untoward incident with the potential to put patients at risk. The challenge for mega-programmes is to handle the multiplicity of such problems. The particular twist is that the 
this web is going to be substantial, and not just because politicians will stand by their policy decisions, but because there is overspill from the weekly political turbulence they have to engage in. Suppliers also feel the need to follow their own and their clients' interests, and are unlikely to publicly criticise developments. Likewise, civil servants and Connecting For Health senior managers responsible for implementing the programmes.

In the second part of the web are the institutions of the NHS itself, related professional institutes and patient representatives. This Greek chorus is obviously concerned about the impacts on the effectiveness of the service, on patient welfare, the allocation of scarce resources in an NHS that has a potentially limitless financial requirement, and the impact of the mega-programme on professional and managerial interests. If members of the first group tend to be 'defenders' of the Programme, this second institutional grouping tend to be 'sympathetic critics' pointing to their local knowledge, the realities of the situation in the NHS and implementation issues, using the espoused benchmarks of efficiency and effectiveness of service and patient care.

The third nexus of institutions that forms a separate Greek chorus constitutes the 'professional critics'. These include the press, audit and accountability bodies, academia and the professional bodies representing, for example, computing or engineering professionals, who feel able to comment in a cautionary way on high-profile developments that touch on their professional knowledge area. Each has a vested interest in commentary and criticism. Each is therefore predisposed to take the relatively simplistic view that a programme should do what it said at the outset. The press knows that bad news sells papers. Editors who pursue such causes win awards (Computer Weekly, 2007). A megaprogramme such as Connecting for Health is an obvious target. It is bound to encounter problems and it will do so over many years. It can become a continuing soap opera providing editorial copy week after week. Straightforward contrasts between initial promises and the changing plan are easily understood by a time-poor readership. Complex discussions over the appropriate judgement to make where every decision is a dilemma make far less compelling reading. In this case, sensationalism is encouraged by the fact that the programme is IT, which every reader knows to be a lost cause, and that it is easy to represent the opportunity cost in emotive terms such as the number of extra hospitals that could have been built.

In one way or another, most mega-programmes are subject to scrutiny and some degree of public accountability (aspects of the War on Terror may be an exception). It may be Shell's need to disclose its increased exposure on its Sakhalin project to the Stock Market or it may be the need to demonstrate best value for taxpayers' money, as in this case. In the UK public sector, the National Audit Office (NAO) and the PAC investigate troubled programmes. Until very recently, both organisations have emphasised their findings of dysfunction, of bad practice rather than good, of failure rather than success. Likewise, auditors in the private sector. Would these bodies have a basis to continue to exist if all they found was excellence? So they have a similar ground to the press for adopting a literal interpretation of what projects and programmes are expected to deliver, viz.

what they promised. In the public sector, this literalism is programme involving the NHS, the political influence in 
also founded in a belief that no penny of public money should be wasted unnecessarily.

It is important to recognise recent qualifications to this argument. The National Audit Office (2006) has published a report on successful public sector IT projects. This signals a shift in its approach to learning from experience so that the need to look at both good and bad is now appreciated. The report was also prepared by the London School of Economics Policy Group, representing an interesting development in how future discourse might be informed and pursued. It does not, however, imply that the National Audit Office (NAO) will be any less literal-minded in its assessments. A second qualification is that the NAO report on the 'The National Programme for IT in the NHS' in 2006 tended to be less critical of progress than the Press, and indeed the PAC, thought it should have been. There is a clear sense, when reading the oral evidence to the PAC on Monday 26 June 2006, that Committee members felt that the NAO report was too influenced by senior NHS executives, including the Director General of IT (see House of Commons Committee of Public Accounts, 2007a).

Academia as an institution can have many positionings on policy and practice issues (Whitley and Hosein, 2007). But one tendency is to believe that it is the guardian of knowledge that practitioners imperfectly apply. Academics, particularly in technical disciplines, tend to view the implementation of their ideas as straightforward and to be intolerant of the argument that practice is messy and complex. (Ironically, the first institutional grouping discussed above also exhibits similar simplifying tendencies, but with differing objectives, about what is in fact a complex, unpredictable 'mangle of practice' (Pickering, 1995).) Academics make a better name for themselves by promoting their 'knowledge' of how to do things right rather than by focussing on practical dilemmas. Either the programme team should have executed more effectively and efficiently, or the programme was set up incorrectly in the first place. The logic is incontrovertible - there are no other alternatives.

There are better ways to engage, of course, but, as we found at the London School of Economics with our work on the UK government's National Identity card scheme (LSE, 2006), their success is dependent also on how other institutions in the wider web choose to conduct the discourse (Whitley et al., 2007). At the LSE case, as noted by its Director Howard Davies (2006), there were accusations of bias from the Home Office and its ministers, a government unforthcoming in providing details of their proposals, and discouragement of 'the kind of rational debate that proposals of this far-reaching nature surely require'. The House of Commons Science and Technology Committee (2006) also took the government and related bodies to task over their attitude to scientific advice, risk and evidence about the scheme.

Be that as it may, the point we come to is that in this third nexus the power of the set of institutions is multiplicative. They not only act independently, they feed off each other. Academics pick up on press reports, the press reports on the NAO and PAC. The PAC reacts to what the NAO says. The press co-opts the PAC chairman and reports his opinion together with academic and professional body opinion, for example that of the
British Computer Society, and so on. It is an institutional web.

Within these three webs, we argue that it is too easy to engage in games of deception of both self and others. We recently heard an ex-cabinet minister talk of a billionpound project he was promoting, 'I knew when I was telling Treasury that it would only cost so much that this was a massive understatement; they knew that I knew this; and I knew that they knew'. In other words everyone was complicit in playing a game that deliberately avoided confronting the question of what would be the actual cost and whether the benefits would be worth it. Those who ultimately fund such programmes, whether they be taxpayers or shareholders, deserve that the key players engage in better quality debate about the real prospects for the programme and greater honesty about the reasons for proceeding.

\section{Confronting the reality}

We have already established that mega-programmes pose management dilemmas that are not readily resolved. It remains to discuss whether mega-programmes are appropriate.

To simplify, there are three options. First, we may believe that mega-programmes are inappropriate. Second, we may believe them appropriate but that stakeholders will never accept the reality that they will not go to plan or deliver what they promise. Third, we may believe that they can be appropriate and that they will achieve better outcomes if stakeholders understand and manage the realities of megaprogrammes, based on previous experiences of their workings.

The first option will be most attractive to those who believe that small is beautiful, and that it is better to carve out well-defined projects with readily achievable benefits. Such projects are manageable with a degree of probability that means that investors can take informed, even if they are not $100 \%$ certain, decisions. Project managers are clear about their targets. Time frames are such that there is less opportunity for volatility to disrupt the project. An advocate of this position also has to hold that megaprogrammes will not on balance deliver as good a set of outcomes as would be achieved through smaller projects. It implies that grand schemes such as the creation of a unique and common medical record or a foolproof identity card for everyone in the UK will always underdeliver and that it is better therefore not to pursue such ambitions via a programme-driven route. The sophisticated advocate might argue that in such cases it is better to work on developing conditions under which stakeholders might choose a convergent rather than divergent route. In other words, some form of standard is developed and incentives provided for adoption of that standard. Achieving the desired end is more by stimulating demand-pull than through resourcing supply-push. There are many advocates of such an approach (for discussions, see Sauer et al., 1997; Willcocks et al., 2002) But ultimately, this reduces to an article of faith as it is rarely if ever possible to compare programme and non-programme approaches in any specific set of circumstances.

The second option depicts the current conventional wisdom. On this view, there are some missions that warrant 
a mega-programme approach. Obvious candidates are matters of public concern such as air traffic control, national security, and, of course, health. Here, for reasons of equity, safety and the like, the argument is that the 'small is beautiful' and the 'demand-pull' routes deliver incomplete coverage and so are compromised. In such cases you require central coordination. The advocate of this option recognises that a programme once launched will not meet original expectations, but is confident that those who have promoted the programme have been able to recognise the ultimate value that can be achieved and are able to make well-balanced judgements as to the appropriateness of pursuing it. This amounts to an argument to put our faith in the experts because they know best, and to not tell the funders the truth because they would be frightened off. In practice, the funders are often lured in with an enticing business case, their initial funds expended and through the psychology of escalating commitment (Keil, 1995; Keil et al., 1998), they are pressured to provide more, accept different scope and functionality, and agree to delayed delivery.

It has been commonplace among project and programme promoters to argue that they could only get the go-ahead by understating the costs and overstating the benefits (Willcocks and Lester, 1999). This cynical approach carries with it the cost that promoters must expect a chorus of criticism from the funders and those players in the institutional web who take responsibility for overseeing and ensuring the appropriate use of funds, be they public or private. To be an advocate of this second option and to complain about criticism is to want to have your cake and eat it.

The third option, which we support, accepts that there may be circumstances under which mega-programmes are required - say where speed, $100 \%$ coverage or overall coordination is essential. Where we differ is in our belief that you can and should have a sensible conversation about the reality of mega-programmes with the funders. Our first reason for saying this is our ex-cabinet minister example in which the Treasury knew that they would be asked for further funding later. Our second is a recent finding by the pollster, Mori, that when the public are exposed to the true complexity of a major issue in government, the percentage willing to leave the judgement in the hands of the experts rises. We interpret this as an indication that the taxpayer, when confronted with the reality of mega-programmes, may well accept that judgements under high levels of uncertainty can be, and are often better, left to the experts. In other words, the key funders, that is the taxpayers through Treasury, are mature enough to engage with the truth. We see no reason for supposing that this would be different in the case of the shareholders and directors of companies.

Honesty has three virtues. First, it is ethical and duly respectful of others' interests. To knowingly misrepresent and 'protect' stakeholders from the truth, that is to deliberately understate the downside and overstate the upside to those whose money is at risk, is arrogant and unethical. Second, honesty engenders better and more supportive relationships with the funders. Untruth damages relationships because whether or not funders believed what was promised, any efforts to re-negotiate will be tinged with adversarialism because of perceived under-performance. The third virtue of honesty is that all parties can then engage in a more open discussion of whether the proposed benefits are worth the costs and risks involved. This has two facets. One is that a more widely informed judgement can be made about whether to proceed. We recognise that this courts the risk that funders may withdraw their support. This puts greater pressure on promoters to adequately justify their programme. If through honest efforts, they are unable to persuade the funders, it is not unreasonable that that the programme be aborted. The other facet is that it helps everyone to prepare for what to do when problems do arise. There is less need for cover-ups and excuses. Scenarios can be developed for alternatives.

To return to the looming presence of the National Programme for IT, it was apparent from the outset to any experienced and unbiased commentator that the programme would encounter many storms and would end up being a different deal for the taxpayer. That it was not transparent to all concerned that initial statements of cost were only for the contracts with LSP not for the total transformation that would be necessary to secure significant benefits from the programme was alone sufficient to give the more critical institutions in the web a target.

The alternative would not have been easy. To have admitted that the full cost would be a multiple of the contract costs, say in the order of £18-20 billion, would have been unattractive to the Government for fear it would be accused of inflating public spending. The very scale implied would have given a hostage to potential institutional critics - who has ever successfully managed anything on this scale? Why should anyone expect an organisation such as the British public service with its reputation for projects to be able to manage successfully such an outlandishly large programme (cf. Dunleavy et al., 2006)? We reiterate what we said more generally earlier, if an adequate case could not be made against such criticisms, then it would have been legitimate to question the appropriateness of proceeding. On the other hand, if the case could have been made in the face of the doubts and risks, with all parties aware of the reality that it could not go to plan or deliver what was originally proposed, then the process of navigating through the storms as they hit would have been eased and the grounds for the current chorus of institutional criticisms removed.

\section{Concluding remarks}

We have argued that it is in the nature of megaprogrammes that they never go to plan or achieve what they initially promise. The conventional approach of securing support by setting unduly high expectations is dysfunctional. There are, however, at least two parties to any programme-funding conversation. Where multiple parties are playing the same game, where funders pretend that they expect the promises to be delivered when they know they cannot be, it is incumbent on all to take the initiative in developing a better quality conversation. Where some parties, taxpayers for example, are less aware of the realities, then the programme management community should take it upon itself to start an education process.

In the specific case of the National Programme for IT, we see nothing that should be surprising in its progress given the nature of the enterprise undertaken. Its supporters, promoters and programme organisation should not be 
surprised at the criticisms currently being levelled. It is all part of a game whose rules are a logical consequence of the way they have chosen to play. They have gifted their opponents in the institutional web not only the ammunition with which to attack them but have also provided the logical and moral basis on which criticisms can be legitimately made.

It is time for the multiple parties to mega-programmes like the National Programme to recognise that all the other parties are intelligent and knowledgeable about programmes as investments and as risks to be managed. Mutual respect and a willingness to talk openly and sensibly about the realities will better serve the interests of the taxpayers and shareholders than continuation of the pretence that there is some significant probability that everything will go exactly as initially proposed. It is time for game-playing to end and mature interaction to begin. And for our part in this process, we have put together the present Special Issue in the belief that the papers published will contribute significantly to the academic, policy and practice debates that will continue to swirl around mega-programmes, and the implementation and use of IT in the NHS.

\section{Note}

1 Presentation by Ben Page, MORI, on the contract between the citizen and the state, at the Public Service Reform Conference 2007: 21st Century Public Services - Learning from the Front Line, at the Queen Elizabeth Conference Centre, Westminster, 27 March 2007.

\section{References}

Computer Weekly (2007). Computer Weekly's NHS Campaign Wins Publishing 'Oscar', Computer Weekly, 15th May, pp. 1, 22.

Davies, H. (2006). Letter to the Prime Minister, archived at http://identity project.lse.ac.uk/daviestoblair.pdf.

Dunleavy, P., Margetts, H., Bastow, S. and Tinkler, J. (2006). Digital Era Governance: IT Corporations, the State and e-Government, Oxford: Oxford University Press.

Flyvbjerg, B., Bruzelius, N. and Rothengatter, W. (2003). Megaprojects and Risk: An Anatomy of Ambition, Cambridge: Cambridge University Press.

House of Commons Committee of Public Accounts (2007a). Department of Health: The National Programme for IT in the NHS, 20th Report, 11th April, The Stationery Office Limited, London.
House of Commons Committee of Public Accounts (2007b). Delivering Successful IT-enabled Business Change, 27th Report, 14th May, The Stationery Office Limited, London.

House of Commons Science and Technology Committee (2006). Identity Card Technologies: Scientific Advice, Risk and Evidence, Sixth Report, 20th July, The Stationery Office, London.

Keil, M. (1995). Pulling the Plug: Software project management and the problem of project escalation, MIS Quarterly 19(4): 421-447.

Keil, M., Cule, P.E., Lyytinen, K. and Schmidt, R.C. (1998). A Framework for Identifying Software Project Risks, Communications of the ACM 41(11): 76-83.

Kling, R. and Scacchi, W. (1982). The Web of Computing: Computer technology as social organization', in M. Yovits (ed.) Advances in Computers, Vol. 21, New York: Academic Press.

London School of Economics (2006). The Identity Project: Research, Update January 2006, Policy Engagement Unit, Information Systems and Innovation Group, LSE, London.

National Audit Office (2006). Achieving Innovation in Central Government Organisations, 25th July, The Stationery Office, London.

Office of Government Commerce (2007). Introduction to Procurement: The Strategic Business Case. http://www.ogc.gov.uk/ business_case_strategic_business_case_2159.asp, as available 20th June 2007.

Sauer, C. (1993). Why Information Systems Fail: A Case Study Approach, Henley-on-Thames, UK: Alfred Waller.

Sauer, C. and Yetton, P. and associates (1997). Steps To The Future, San Francisco: Jossey Bass.

Sauer, C., Gemino, A. and Reich, B. (2007). Managing Projects for Success: The Impact of Size and Volatility on IT Project Performance, Communications of the ACM, 50 (November): forthcoming.

Whitley, E. and Hosein, I. (2007, June). Policy Engagement as Rigourous and Relevant Information Systems Research: The Case of the LSE Identity Project, Paper presented at the Proceedings of the 15th European Conference on Information Systems, St. Gallen.

Whitley, E.A., Hosein, I.R., Angell, I.O. and Davies, S. (2007). Reflections on the Academic Policy Analysis Process and the UK Identity Cards Scheme, The Information Society 23(1): 51-58.

Willcocks, L. and Graeser, V. (2001). Delivering IT and e-Business Value, Oxford: Blackwell.

Willcocks, L. and Griffiths, C. (1994). Predicting Risk of Failure in Large-Scale IT Projects, Technological Forecasting and Social Change 27(2): 205-228.

Willcocks, L. and Lacity, M. (2006). Global Sourcing of Business and IT Services, London: Palgrave.

Willcocks, L. and Lester, S. (eds.) (1999). Beyond the IT Productivity Paradox, Chichester: Wiley.

Willcocks, L., Petherbridge, P. and Olson, N. (2002). Making IT Count: Strategy, Delivery and Infrastructure, Oxford: Butterworth. 